\title{
Redescription of Lemuricola (Madoxyuris) bauchoti (Nematoda, Oxyuridae) from Lemur catta in Madagascar
}

\author{
María del Rosario Robles ${ }^{*}$, James E. Loudon², John M. Kinsella ${ }^{3}$, Mandala Hunter-Ishikawa ${ }^{4}$, \\ David S. Miller ${ }^{4}$, Michelle L. Sauther ${ }^{2}$ and Frank P. Cuozzo ${ }^{5}$
}

\begin{abstract}
${ }^{1}$ Centro de Estudios Parasitológicos y de Vectores CEPAVE (CCT-CONICET-La Plata) (UNLP), Calle 2 \# 584 La Plata (1900), Buenos Aires, Argentina; ${ }^{2}$ Department of Anthropology, University of Colorado, Boulder, CO 80309, USA; ${ }^{3}$ HelmWest Laboratory, 2108 Hilda Avenue, Missoula, MT 59801, USA; ${ }^{4}$ College of Veterinary Medicine and Biomedical Sciences, Colorado State University, Fort Collins, CO 80524, USA; 5 Department of Anthropology, University of North Dakota, Grand Forks, ND 58202, USA
\end{abstract}

\begin{abstract}
Lemuricola (Madoxyuris) bauchoti Chabaud, Brygoo et Petter, 1965 is redescribed from material collected from the ring-tailed lemur, Lemur catta, from the Beza Mahafaly Special Reserve in Madagascar using the scanning electron microscope. This is a new host record and the first oxyurid reported from the ring-tailed lemur. Previously, records of each species of the subgenus Madoxyuris have been restricted to a single host species, but the close relationship between these nematodes and their Strepsirrhini hosts will only be proven when additional records fill in the gaps in their distribution.
\end{abstract}

\section{Keywords}

Lemuricola (Madoxyuris) bauchoti, Oxyuridae, ring-tailed lemur, Lemur catta, Hapalemur, Madagascar, SEM

\section{Introduction}

Species of Oxyuridae (Nematoda) can be found in most families and genera of the order Primates. The subfamily Enterobiinae was erected for oxyurids from primates (Hugot et al. 1996), and the monophyly of this subfamily was later confirmed by cladistic analysis (Hugot 1999). Primates of the suborder Strepsirrhini are parasitized by species of the genus Lemuricola Chabaud et Petter, 1959 (Enterobiinae).

Several authors have studied the possible coevolutionary relationships among groups of primates and their oxyurid parasites (e.g. Cameron 1929, Sandosham 1950, Inglis 1961, Brooks and Glen 1982, Hugot 1999). Among these, Hugot (1999) provides evidence supporting the existence of coevolution with cospeciation between hosts in Strepsirrhini and species of Lemuricola. Several occurrences of parasites specific to particular hosts were observed, and for this reason it is probable that the speciation of the parasites parallels very closely the speciation of the hosts (Hugot 1999). However, these studies are based on relatively few host species. To date, Lemuricola spp. have been recorded from only 10 of 88 host species of Strepsirrhini belonging to 7 of 23 genera and 4 of 7 families.

On the basis of cephalic and caudal papillae as well as characteristics of the lips, oesophagus and tip of the tail of males, three subgenera of Lemuricola have been defined
(Chabaud and Petter 1959, Inglis 1961, Chabaud et al. 1965). To date, 9 species have been described: L. nycticebi (Baylis, 1928 ) and L. malayensis Inglis et Dunn, 1963 belong to the subgenus Protenterobius Inglis, $1961 ;$ L. contagiosus Chabaud et Petter, 1959 and L. microcebi Hugot, Morand et Gardner, 1995 belong to the subgenus Lemuricola Chabaud et Petter, 1965; and L. lemuris (Baer, 1935), L. vauceli Chabaud, Brygoo et Petter, 1965, L. baltazardi Chabaud, Brygoo et Petter, 1965, L. bauchoti Chabaud, Brygoo et Petter, 1965 and L. daubentoniae Petter, Chabaud, Delavenay et Brygoo, 1972 belong to the subgenus Madoxyuris Chabaud, Brygoo et Petter, 1965. Based on cladistic studies, Hugot and Baylac (2007) question the placement of $L$. daubentoniae in the subgenus Madoxyuris, suggesting that it is more closely related to the subgenus Lemuricola.

The males of each genus and subgenus of Enterobiinae have been observed to share a particular pattern of distribution of preanal and postanal papillae (Hugot and Baylac 2007). These caudal papillae as well as other features of the tail are very difficult to observe with light microscopy. Only two studies on Enterobiinae have studied these features with scanning electron microscopy (SEM) (Tenora et al. 1981, Baruš et al. 2007).

Lemuricola (Madoxyuris) bauchoti Chabaud, Brygoo et Petter, 1965 was described on the basis of specimens recov- 


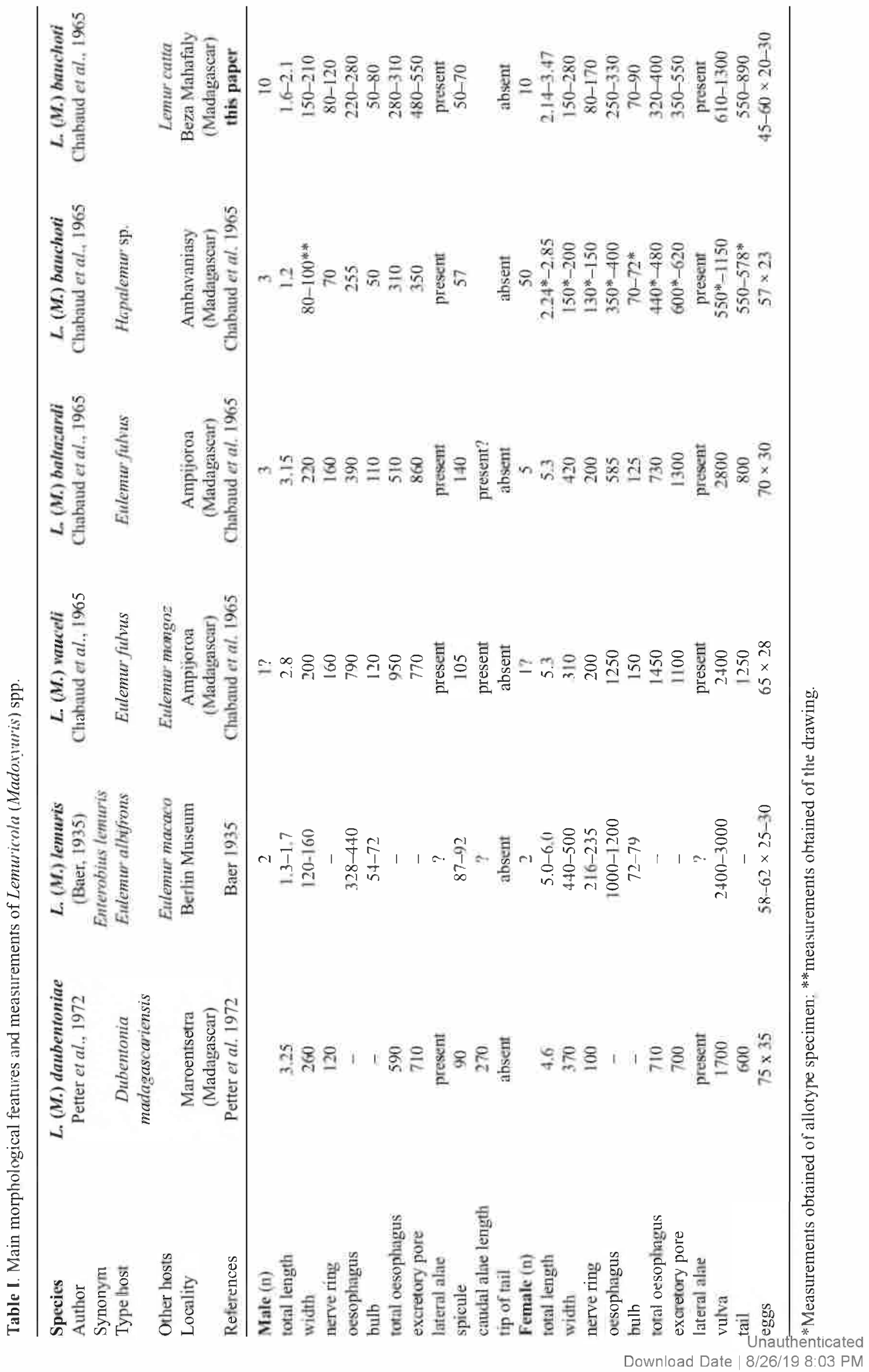


ered from Hapalemur spp. In this previous work, some characteristics were not mentioned, the drawings of the posterior end were not very clear and a correct differentiation from other species was not provided.

No species of Enterobiinae have been previously recorded from the ring-tailed lemur, Lemur catta Linneaus, 1758. The aim of this paper is to redescribe Lemuricola (Madoxyuris) bauchoti on the basis of new specimens recovered from this host from southwest Madagascar.

\section{Materials and methods}

The nematodes studied here were collected on 17 December 2005 from the feces of a ring-tailed lemur, Lemur catta, from the Beza Mahafaly Special Reserve in Madagascar (233 $30^{\prime} \mathrm{S}$, $\left.44^{\circ} 40^{\prime} \mathrm{E}\right)$. The feces were collected immediately after observing the individual defecating during the morning hours (07-10 a.m.) and preserved in polyvinyl alcohol. Nematodes were studied in temporary mounts of lactophenol. Drawings were

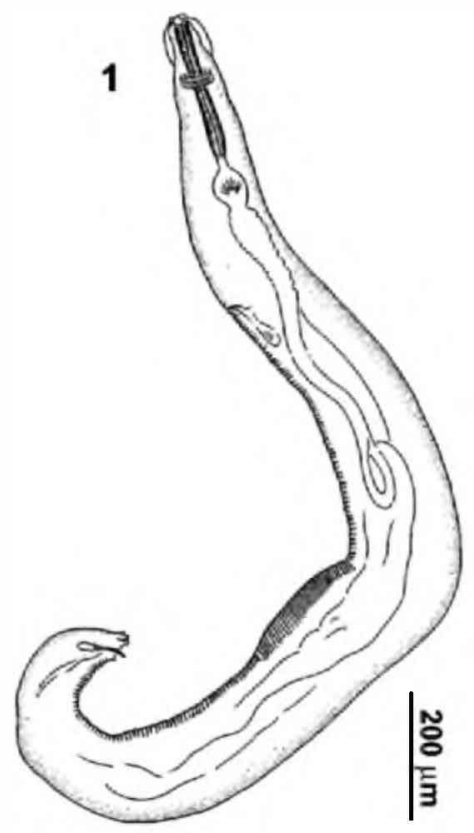

2
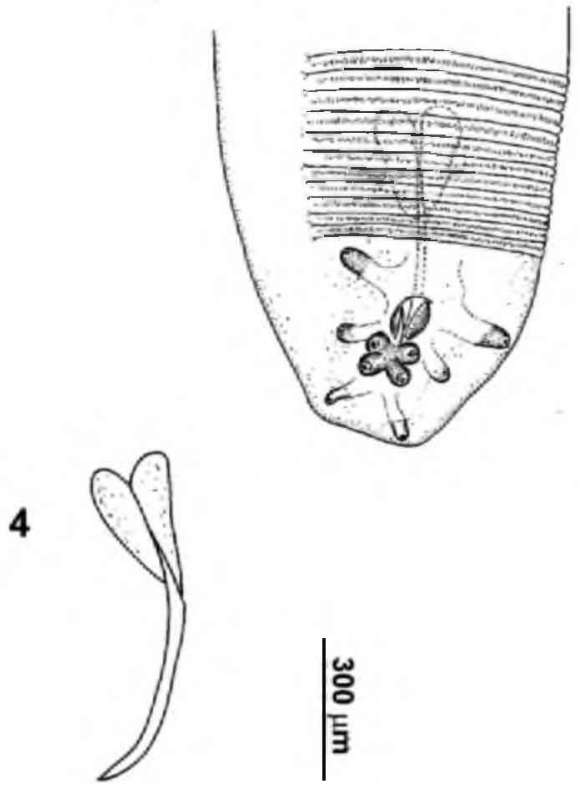

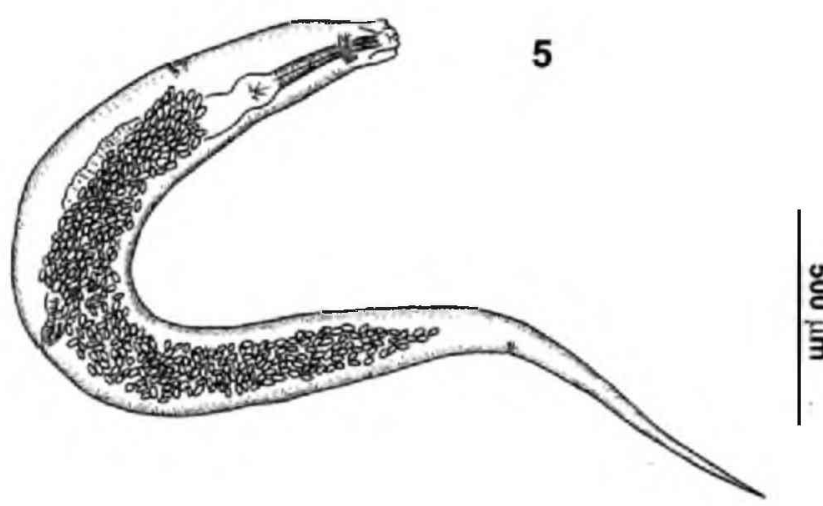

6

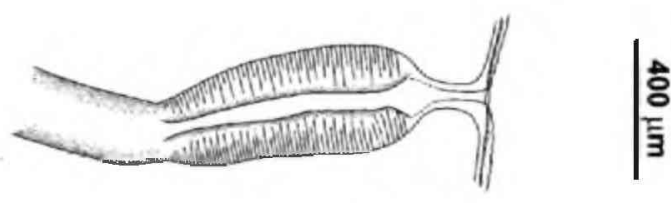

3
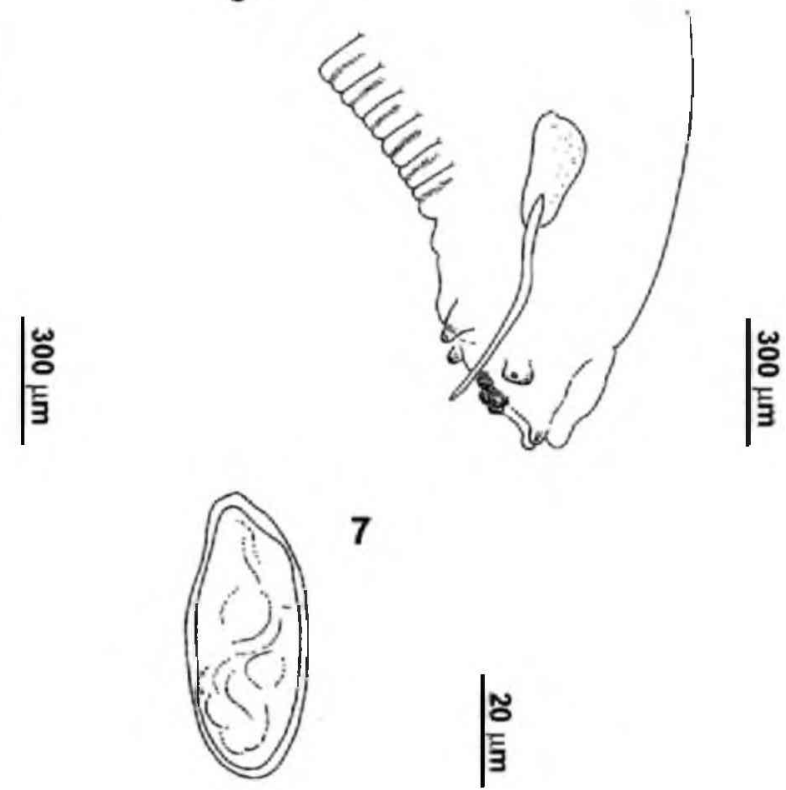

$\mid \begin{aligned} & \text { o } \\ & \text { E }\end{aligned}$

Figs 1-7. Lemuricola (Madoxyuris) bauchoti: 1 - male, complete specimen; 2 - ventral view of posterior extremity, detail of caudal papillae, spicule and area rugosa; $\mathbf{3}$ - posterior extremity, lateral view; 4 -detail of spicule; $\mathbf{5}$ - female, complete specimen; $\mathbf{6}$ - detail of vulva; 7 - egg 
made with the aid of a drawing tube. Some specimens were dried using the critical point method, examined under SEM (Jeol $6360 \mathrm{LV}$ ), and photographed.

All measurements are in micrometers unless otherwise stated (Table I).
The type specimen of Lemuricola (Madoxyuris) bauchoti from Hapalemur spp. was studied (1 female allotype, MNHN 634 F Muséum National d'Histoire Naturelle, Paris, France this is the only type material existent of this species).
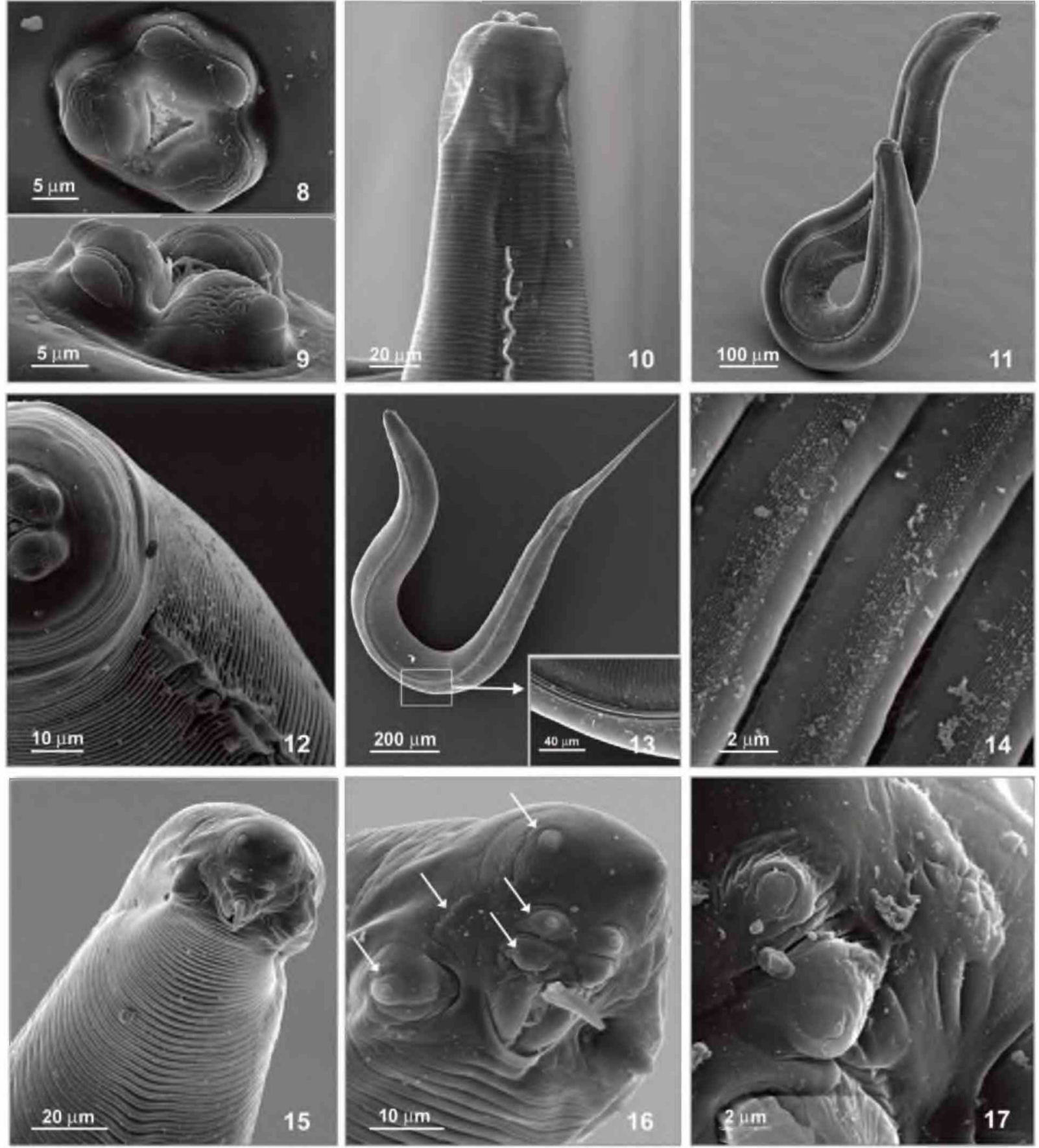

Figs 8-17. SEM micrographs of Lemuricola (Madoxyuris) bauchoti: 8 - female, buccal aperture surrounded by lips, four cephalic papillae and amphids, apical view; 9 - female, lateral view of anterior extremity, detail of cephalic papillae and amphids; 10 - male, lateral view of anterior extremity, detail of lateral alae; 11 - male, complete specimen; 12 - female, lateral view of anterior extremity, detail of lateral alae; 13 - female, complete specimen, detail of lateral alae; 14 - male, detail of area rugosa; 15 - male, ventral view of posterior extremity and area rugosa; 16 - male, 2 pairs of pedunculate papillae, 2 pairs of sessile papillae, and 1 pair of amphids; 17 - male, detail of sessile papillae and amphids 


\section{Redescription}

Lemuricola (Madoxyuris) bauchoti Chabaud, Brygoo et Petter, 1965 (Figs 1-17, Table I)

General: Buccal aperture surrounded by three lips. Lips defined, with cuticular edges around triangular opening (Figs 8 and 9). Four cephalic papillae visible and ventral papillae very close to the amphids (Figs 8 and 9). Lateral alae symmetrical and with sexual dimorphism. In males, the alae are single expansions (one crest) of the cuticle and extend from approximately $350-420 \mathrm{~mm}$ from the posterior end to approximately $3 / 4$ of the body length (Figs 10 and 11); in females, the alae are double expansions (two crests) reaching the end of the body (Figs 12 and 13).

Male: Body length $1.2-2.1 \mathrm{~mm}$. Body width $80-210$. Total oesophagus 280-310 long, oesophageal bulb 50-80 long. Nerve-ring 70-120, and excretory pore 350-550 from anterior end (Fig. 1). Spicule 50-70 long (Figs 2-4). Tail spike absent (Figs 2 and 3).

Area rugosa present as a large round inflated cuticle posterior to the excretory pore, in the region between the second and third portion of body (Figs $1-3 ; 14$ and 15 ).

Four pairs of caudal papillae: 1 preanal pedunculate pair, 2 postanal sessile pairs, and 1 large postanal pedunculate pair supporting the bursa (Figs 2 and 3,15 and 16). The 2 sessile pairs are very close to each other and form a square cuticularized sheet connected with a small pitchfork ornamentation that longitudinally flanks the posterior edge of the cloaca (Figs 16 and 17). The phasmids are lateral to the first papillae and lie between the two pedunculate papillae (Fig. 17).

Female: Body length 2.14-3.47 mm. Body width 150-280. Total oesophagus 320-480 long, oesophageal bulb 70-90 long (Fig. 5). Nerve-ring 80-170, excretory pore $350-620$, and vulva 550-1300 from anterior end (Figs 5 and 6). Tail relatively long, 550-890. Eggs elliptical and with large operculum, 45-60 × 20-30 (Fig. 7).

Type host: Hapalemur spp.

New host: Lemur catta Linnaeus, 1758 (Lemuridae).

Type locality: Ambavaniasy, east-central Madagascar.

New locality: Beza Mahafaly Special Reserve in Madagascar $\left(23^{\circ} 30^{\circ} \mathrm{S}, 44^{\circ} 40^{\prime} \mathrm{E}\right)$.

Site of infection: Presumptively caecum. Found in feces.

Specimens deposited: Helminthological Collection of the Museo de La Plata CHMLP, no. is MLP 6146.

Remarks: The general morphology and measurements of the specimens of $L$. (M.) bauchoti from $L$. catta examined in the present study agree with specimens from Hapalemur spp. described by Chabaud et al. (1965) and the observations made here on the allotype specimen with a few exceptions. The minor discrepancies include small differences in the measurements of the excretory pore in both sexes and the total length of the oesophagus in the females (Table I).

The principal character which places these specimens in the subgenus Madoxyuris is the absence of a tail spike in the males. They can be differentiated from the other 4 species in the subgenus by their shorter oesophageal and spicule lengths. In addition, the males differ from $L$. (M.) daubentoniae, $L$. (M.) vauceli, and $L$. (M.) baltazardi by lacking caudal alae and by a more anterior excretory pore. The shorter distance from the vulva to the anterior end distinguishes the females from $L$. (M.) lemuris, $L$. (M.) vauceli, and $L$. (M.) baltazardi. Although the males are somewhat longer than the original description and there are other minor differences in measurements, we believe they most closely fit $L$. (M.) bauchoti.

\section{Discussion}

This is the first record of Lemuricola (Madoxyuris) bauchoti from Lemur catta and the first record of any oxyurid from this host. Structures such as the cephalic papillae, details and distribution of the caudal papillae and amphids, fine points of the cervical alae, and the area rugosa, poorly visualized under light microscopy, were observed here with the SEM for the first time.

Using light microscopy, Chabaud et al. (1965) described 3 pairs of pedunculate papillae, 2 pairs of sessile papillae, and 1 pair of amphids in $L$. (M.) bauchoti as well as $L$. (M.) vauceli and $L$. (M.) baltazardi. Only 2 pairs of pedunculate and 2 pairs of sessile papillae were observed here using SEM. There is no small pair of pedunculate papillae lateral to the anus as described by Chabaud et al., although there is a small ridge in this area (Fig. 15). Since the number of observed papillae in the Enterobiinae is constant, this feature should be re-examined in the species $L$. (M.) vauceli and $L$. (M.) baltazardi.

To date, all species in the subgenus Madoxyuris have been recorded from the family Lemuridae and each species has been described from a different species of host (Hugot and Baylac 2007). Chabaud et al. (1965) list the type host of L. bauchoti only as Hapalemur spp., but Hugot and Baylac (2007) give the type host as Hapalemur simus without any further explanation. In any case, ours is the first record of a species of Lemuricola from a host genus different from the original, which contradicts the coevolutionary theories of a number of authors (Cameron 1929, Sandosham 1950, Inglis 1961, Brooks and Glen 1982, Hugot 1999). However, a number of studies support a close phyletic affinity between Lemur catta and the genus Hapalemur (e.g. Crovella and Rumpler 1992, Macedonia and Stanger 1994, Yoder and Irwin 1999, Delpero et al. 2001), agreeing in part with the theories about a possible association by descent between Lemuricola and species of Strepsirrhini.

Future records of Enterobiinae in lemurs will reduce the gaps in their host distribution, and will prove or disprove the degree of correspondence between parasite and host phylogeny.

Acknowledgments. This research was supported by a grant from the National Science Foundation (BSC 0525109). We thank the follow- 
ing people for supporting this research: Jeannin Ranaivonasy, Andry Randrianandrasana, Joel Ratsirarson, Jeannicq Randrianarisoa, and Youssouf Jacky Ibrahim. This research was supported by the Association Nationale pour la Gestion des Aires Protégées, the body governing research in Madagascar's protected areas, and the Département des Eaux et Forêts, Ecole Supérieure des Sciences Agronomiques. We thank Dana Whitelaw and members of the Beza Mahafaly Ecological Monitoring Team, especially Elahavelo and Enafa Efitroaromy. Special thanks to Jean Pierre Hugot for important suggestions on taxonomy. We also thank María Cristina Estivariz (CEPAVE-CCT-CONICET) for the drawings; and to Patricia Sarmiento (MLP-UNLP) for the SEM photographs.

\section{References}

Baer J.G.S. 1935. Etudes de quelques helminthes de lémuriens Revue Suisse de Zoologie, 42, 275-292.

Baruš V., Foitová I., Koubková B., Hodová I., Simková A., Nurcahyo W. 2007. A new nematode, Pongobius hugoti gen. et sp. n. from the orangutan, Pongo abelii (Primates: Hominidae). Helminthologia, 44, 162-169. DOI: 10.2478/s11687-007-0026-4.

Brooks D.R., Glen D.R. 1982. Pinworms and Primates: a case study in coevolution. Proceedings of the Helminthological Society of Washington. 49, 76-85.

Cameron T.W. 1929. The species of Enterobius Leach, in Primates. Journal of Helminthology, 7. 161-182. DOI: 10.1017/S0022 149X00018770.

Chabaud A.G., Brygoo E.R., Petter A.J. 1965. Les nématodes parasites de lémuriens Malgaches. VI. Description de six espèces nouvelles et conclusion générales. Annales de Parasitologie Humaine et Comparée, 40, 181-214.

Chabaud A.G., Petter A.J. 1959. Les nématodes parasites de lémuriens Malgaches. II. Un nouvel Oxyure: Lemuricola contagiosus. Mémoires de l'Institut Scientifique de Madagascar, Ser. $A, 13,127-132$.
Crovella S., Rumpler Y. 1992. Confirmation of the specific status of Hapalemur aureus (Primates: Strepsirrhini) by restriction genomic DNA banding patterns. Human Evolution, 7, 63-67.

Delpero M., Masters J.C., Cervella P., Crovella S., Ardito G., Rumpler Y. 2001. Phylogenetic relationships among the Malagasy lemuriforms (Primates: Strepsirrhini) as indicated by mitochondrial sequence data from the 12S rRNA gene. Zoological Journal of the Linnean Society, 132, 83-103. DOI: 10.1111/ j.1096-3642.2001.tb00624.x.

Hugot J.P. 1999. Primates and their pinworm parasites: the Cameron hypothesis revisited. Systematic Biology, 48, 523-546. DOI: $10.1080 / 106351599260120$

Hugot J.P., Baylac M. 2007. Shape patterns of genital papillae in pinworms (Enterobiinae, Oxyurida, Nematoda) parasite of primates: A landmark analysis. Infection. Genetics and Evolution, 7, 168-179. DOI: 10.1016/j.meegid.2006.08.001.

Hugot J.P., Gardner S.L., Morand S. 1996. The Enterobiinae subfam. nov. (Nematoda, Oxyurida) pinworm parasites of primates and rodents. International Journal for Parasitology, 26, 147159. DOI: $10.1016 / 0020-7519(95) 00108-5$

Inglis W.G. 1961. The oxyurids parasites (Nematoda) of primates. Proceedings of the Zoological Society of London, 136, 103-122.

Macedonia J.M., Stanger K.F. 1994. Phylogeny of the Lemuridae revisited: Evidence from communication signals. Folia Primatologica, 63, 1-43. DOI: 10.1159/000156787.

Sandosham A.A. 1950. On Enterobius vermicularis (Linnaeus, 1758) and some related species from primates and rodents. Journal of Helminthology, 24, 171-204. DOI: 10.1017/S0022149X 00019246.

Tenora F., Baruŝ V., Wiger R., Ryšavỳ B. 1981. Scanning electron microscopic studies on nematode species of the genera Passalurus, Enterobius, and Lemuricola (Oxyurida). Acta Universitatis Agriculturae Facultas Agronomica, 29, 327-339.

Yoder A.D., Irwin J.A. 1999. Phylogeny of the Lemuridae: Effects of character and taxon sampling on resolution of species relationships within Eulemur. Cladistics, 15, 351-361. DOI: 10.1111/j.1096-0031.1999.tb00271.x. 